\title{
SOME REMARKS ABOUT DEFLATION IN THE CASE OF JAPAN
}

\author{
dott. Giovanni COSSIGA ${ }^{1 *}$
}

*1 Presidente sindaci Policlinico Umberto I Università degli Studi "La Sapienza “- ROMA Abitazione - Via Romolo Gigliozzi, 18100128-RO M A, E-mail-g.cossiga@alice.it,Tel. 3803298982

*Corresponding Author: -

Email: g.cossiga@alice.it

\begin{abstract}
: -
The paper would like to examine the long stagnation of the Japanese economy facing the deflation, so trying to find a possible explanation, beyond the argument pointing into a possible liquidity trap. Afterwards, we are examining the course of the main variables from 1985 to present days, on the assumption that not efficacious correction of the boom excesses - concluded unsuccessfully the attempt of the Prime Minister Hashimoto to call into equilibrium the Japanese economic instability - would be responsible for the longtime-stagnant economy. The country in the nineties continued to grow at a slow pace, so that the first recession occurs only in 1998 in connection with the crisis in Southeast Asia. In other words, the correction of the excesses of the boom by means of a creative recession, Schumpeter model, did not take place. The economy has remained unstable. It is assumed in fact that by the early 2000s, within the endless flow of Keynesian interventions and liquidity to support the economy has not yielded the expected results. In contradiction occurred weakening economy and deflation. The increase in non-stop public debt and liquidity appear to have played a role of third wheel, between declining economic performance and price trend in deflation. Finally, through the econometric tools, the effects of excessive public debt on economic activity and deflation are also examined.
\end{abstract}

Keywords: - Deflation, Instability, Financial Crisis, speculative bubble, unconventional monetary measures

\section{(c) $\$(1)$}




\section{INTRODUCTION}

The story of the Japanese economy starting from the nineties can be useful in order to decode the today facts, especially for America and Europe struggling with the impact of 1998-1999 financial crisis. The issue is to try to understand how not to fall into the trap of a poor growth and of mini-recessions within an economic environment dominated by deflation. With a look to the Japan of the last twenty years, deflation and economy in midstream seem to be the coming years great concern for western economies. It is undeniable that a deflationary environment is resulting into a weak economy and therefore, it can be envisaged a direct correlation between weak economy trends and zero or even negative inflation. Based on this possible link, we could argue that whenever we manage to make the economy to restart, then also the deflation tendency will lose its strength.

With alternate phases, Japan has made an extensive use of monetary policy and government interventions to push the recovery so that the economy would be able to self-supporting; nevertheless, the results have been somehow uncertain. To escape the deflation hold, which in the United States has raised up during the biennium 1998-99, the Fed did not hesitate to promote new measures to support the economy through extraordinary procedures such as the Quantitative Easing $(\mathrm{QE})^{1}$. Measures that really can have some effects for the deflation control, as will be mentioned later. First of all, we point out that, in an unstable environment, the economy performance (the conjuncture cycle) is linked to the performance of inflation or deflation, which are linked to the conjuncture ${ }^{2}$. An economy is unstable if and when is derailing from the regularity and efficiency of the healthy economy, like for instance the attempt to live far too long beyond our means. In an unstable economic subject, however, the natural tendency for a return to normality does not seem to disappear. Therefore, economic systems - we believe - are showing a natural tendency to stability, which is obviously seen as the perfection state of the economy. Then we should consider that whenever an economy has fallen into the instability trap, some virtuous systems for a gradual return to the natural state could be activated in a natural way. Unfortunately, the return to stability is not free at all and is requiring hard fee.

Now, for the stability gradual recovery following a natural course, it is crucial the transitory connection created between the cyclical inflation or deflation and the economy performance (tending to recession). Shortly, in case of instability driving a system to deflation, the natural correlation activated between economic recession and negative inflation proceeding in strict accordance - seems potentially able to absorb the amount of virtual (or evanescent) economy created by an exuberant debt level. Therefore, we have to identify "virtual" with that part of the economy supported by an unguaranteed debt developed within a speculative context. The natural way to a recovered economic stability seems to follow an implicit mathematical model to absorb the excesses and this could improve the timing of the corrective action, even though it would be traumatizing for the economic and social environment.

Therapies to control the instability implemented by the economic and monetary policy, have instead the objective to limit the damage as much as possible during the return way toward stability. These intervention tools, however, cannot move in direct collision with the natural process. They shall be acting rather like a relief considering the concurrent activities implemented by the automatic mechanisms. In other words, it's unrealistic to believe that deflation, which is a real economy product, can be defeated by monetary instruments. Also because in this way, we can collide with the natural mechanism aiming to correct the economy mistakes.

Following the criterion of interventions moving in a way compatible with the correction natural process, the maneuvers of QE may have some effects, though only indirectly, in the deflation restraint. In fact, the very strict and primary link between economy (in recession) and deflation, created within an unstable economy, is not altered at all by the Central Bank interventions provided to introduce liquidity into the system. The additional cash, however, can allow softening the economy fall. The eventual recovery of the economy is reflected later on deflation, which consequently becomes lighter. In other words, the easing of the recession grip does control the price decline that is linked, in a firm bilateral relationship, to the economy cycle.

According to this view, the Federal Reserve challenge in supporting the post-financial crisis US economy weakness by deploying unconventional interventions of monetary policy, showed to have some success chances. At this regard, we should not undervalue the experience of Japan that instead does not seem to have achieved equal benefits from the use of monetary policy unconventional measures. So where is the virtue? Actually, both the Fed and the Bank of Japan could be right. Within the American context, the remarkable results achieved by the banking system initiatives of support and guarantee, have encouraged the Fed to continue on this course. Instead, in the case of Japan the desired effects weren't achieved: not by the measures supporting the banking system, adopted too late and partially, nor by the new liquidity introduced into the system, rising quickly only in 1995 and then again accelerated in 2000 first five years.

Monetary operations have the opportunity to impact positively in an unstable economy, if they can produce positive effects principally on the real economy. It does not seem realistic then to suppose that unconventional monetary maneuvers can have a direct impact on the deflation profile within an economy such as the Japanese, for over a decade under continuous maneuvers that have accentuated its instability. Therefore, it seems confirmed the theory that it is not permitted to directly influence the strong and unidirectional strict relationship between economic trends (tending to recession) and deflation. A significant increase in liquidity, then, could be ineffective, exception made for some improvement in the declining economy. It is the recession strength that is pushing down prices, so that acting according to the correlated direction of the relationship between the two variables, the recession decrease will be reflected consequently on deflation, which thereby is weakened.

The usual measure to support the economy is the use of fiscal policy to strengthen the aggregate demand. Even if Keynesian measures are used to support the economy, the deficit and public debt increase do not affect the very strict and integral relationship between recession and deflation. At this regard, there is the hypothesis that the supporting action 
taken through a public debt increase may produce an appreciable result only in the case of almost virtuous countries, with a low level of public debt and in any case under the 80-90\% in terms of GDP. Therefore, the liquidity increase has no direct effect on the nominal price trend, though only indirectly may finally release the deflation hold, if an economic situation improvement would be reflected on prices.

Instead, for those countries with a very high public debt, this escape from deflation appears to be blocked, because the high debt becomes a third unusual element in the relationship between recession and deflation. Consequently, the upward variation in the heavy indebtedness is reflected immediately and negatively both on the weak economy and on falling prices. Therefore, the cumulative effect of a debt variation to support the economy is weak and even negative, because the modest improvement due to the increased demand is balanced by the decrease occurring through the triangular relationship between the economy (tending to recession), the deflation and the public debt. Indeed, for countries with public debt in excess, Keynesian maneuvers could not produce appreciable effects on the economy and deflation.

In the paper we are sustaining the thesis that Japan, for over a decade exposed to deflation, is blocked in this limbo-state for the primary cause of the economic system dependence from excessive public debt. The increased available liquidity coming from the deficit spending has a neutral effect on prices, which are standing at a deflationary level. At the same time, the public spending pressure probably does not cause any uncertainty effect on private investment, given a nearzero level of the actual interest rate. Nevertheless, it is not able to affect the economy course, for the balancing effect caused by the negative pressure of the rising public debt on the relationship between the conjuncture, tending to recession, and the prices in deflation.

\section{1. - The Japanese anomaly}

The relationship somehow anomalous, generated by the balance of push-and-pull caused by the periodic financing mechanism of public spending, is providing an acceptable justification for the Japanese economy peculiarities. Nonetheless, let us follow an order in our exposition. First of all, we note that the Japanese economy does not fall into recession when the boom (though not disruptive) is exploding. The growth is at a zero level but almost only in 1995, then remaining at an average of $1.6 \%$ from 1991 to 1997 . The recession of the early $1998(-2.05 \%)$ is just a late fringe of the financial crisis and is appearing only as a result of the government decision, giving a stroke to the fiscal policy with a hard action to contain the public imbalance. ${ }^{3}$ So here we have a double peculiarity in the Japanese economy behaviour: a financial crisis without a severe recession; nonetheless, the recession will occur only many years later, when Prime Minister Ryutaro Hashimoto, a true reformer for Japan, adopted some bitter solutions by severely cutting public budgets and through a taxation increasing.

One could argue that after the severe economic slump in Japanese economy, the recession has been avoided because the domestic consumption fall and the value of assets were alleviated by the export-oriented nature of its economy. From the Graph n. 1, we can quite understand how the international conjuncture, reflected in the performance of current accounts, is influencing the internal economic climate. In fact, the consumption is declining rapidly, anyway remaining within a positive area. From 1994, it seems to attempt a rise, then declining during the recession time. Wider instead the oscillation of industrial production which, however, is showing more evident its fall after the bubble burst and during the recessions of 1998 and 2001 (this one slightly weaker). The recovery in the years after 2005 is related to the fake recovery of the American and world economy, until the 2008-2009 crisis.

It should be useful the comparison with the America of the boom years and of the 2008-2009 financial crisis. From the Graph n. 2, it can be observed that in the US the consumption fall due to the crisis is much more incisive and is becoming negative when compared with the years pre-crisis (in 2009, -1.60\% against the previous year). Moreover, the drop in industrial production is much deeper, while the deficit of current accounts is halved if compared to 2007.

\section{Graph n. 1}

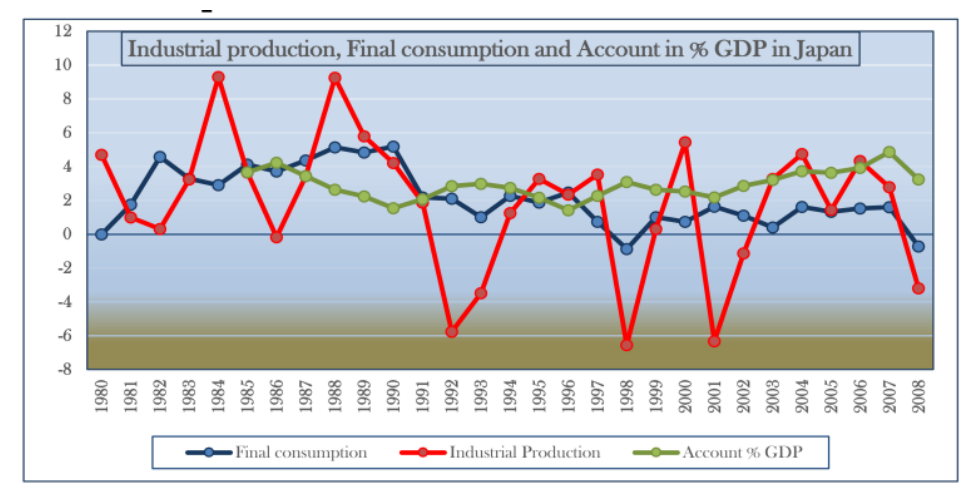

* Based on OECD data

** Variation in Production and Consumption from previous year; Current Accounts in \% of PIL 


\section{Graph n. 2}

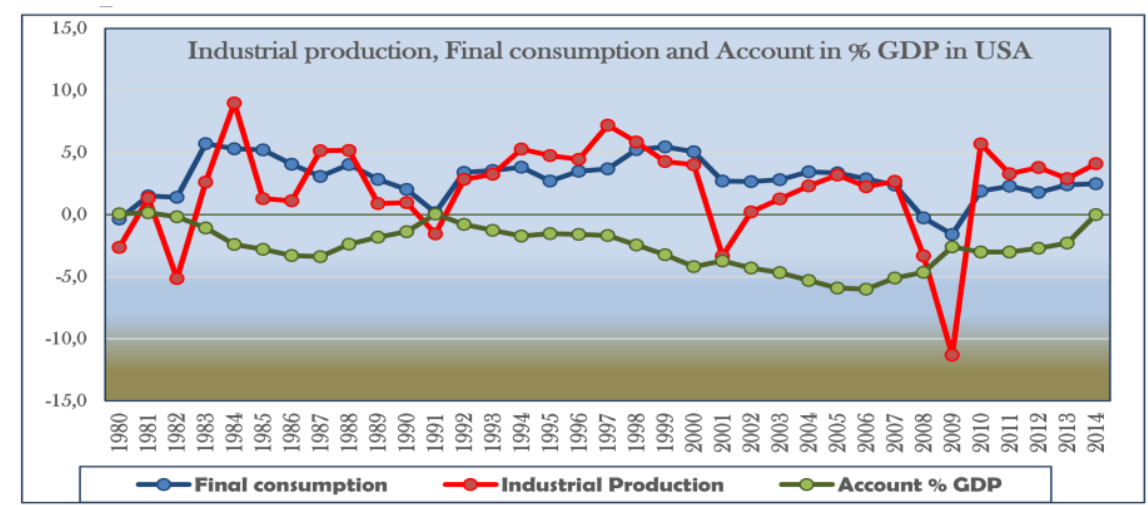

* Based on OECD data

** Variation in Production and Consumption from previous year; Current Accounts in \% of PIL

The comparison is highlighting the objective difference between the evolution of the two post-boom financial crises, in the United States and Japan. However, this approach does not seem enough to understand the reasons for the long stall of the Rising Sun economy, even more if we compare the different course of America in its promising battle for a return to prosperity.

For the research of the reasons for the long stalemate, it seems appropriate to investigate the behaviour of the single variables and to study the interferences each one of them could suffer due to the profile assumed by the others. For example, the Japanese economy deflation is not a phenomenon generated by the heavy slump and the financial crisis. By the way, a feeble tendency to deflation in Japan is already evident since the second half of the 80s, when inflation is essentially zero, then going up to an average of $2 \%$ at the end of the decade, coinciding with the boom irrational force.

\section{Graphs n.3}

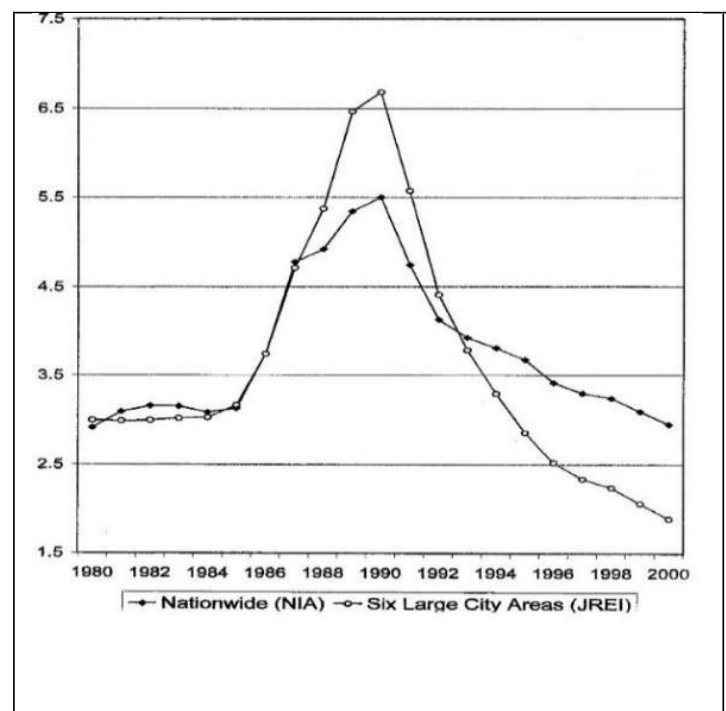

Land: - indices 1980-2000

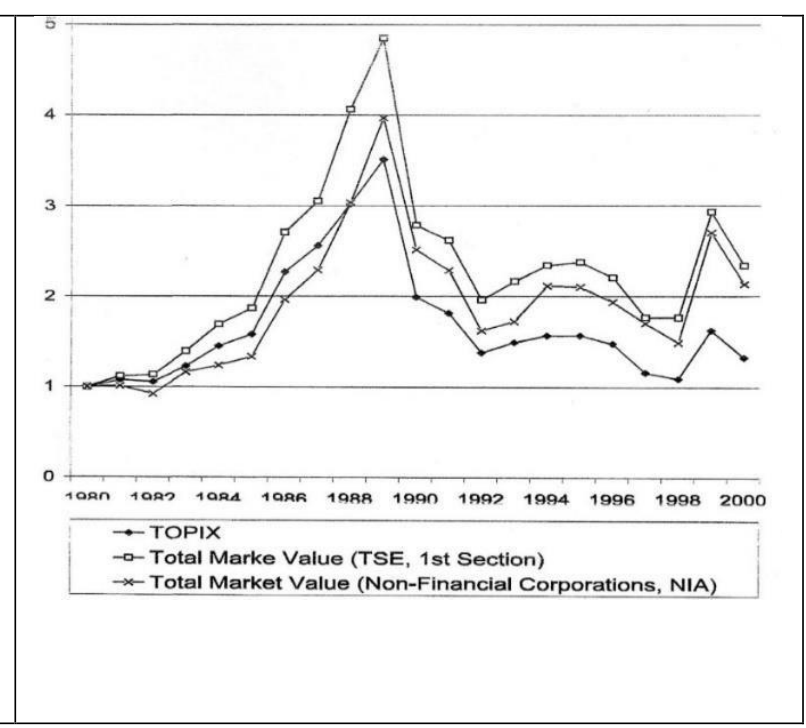

Share value: 1980 -2000 (rates to nominal PNL) Source: Asset Price Fluctuations in Japan: 1980 -2000, Tomoyuky Nakajima - Brown University, Dec. 2003

With the financial crisis outbreak, the price decreases in Japan are slow and will reset only in 1995, unlike the US financial crisis where consumer prices are falling from $1.3 \%$ in 2009 to $-0.7 \%$ in 2010 (see Graph n. 4). The price trends in Japan become definitely deflationary since 1995, only excluding some short inflation jumps in 1997 and 2008 stimulated perhaps by Southeast Asia effervescence firstly and then by the West area speculative boom. Essentially, from 1991 to 1995 the inflation profile in slow decline seems to be moving in parallel with the slow boom decrease (real estate values being reduced up to $50 \%$ in 1994). See again Graph n. 3.

In addition, the unusual gradual decline of inflation until the zero level in 1995 seems to be linked anyhow to the new liquidity introduced into the economy, increasing progressively up to double in 2000 compared to 1990 and then accelerating again until 2006. The Graph $\mathrm{n} .5$ is showing the rapid growth of liquidity (M1) in Japan compared with the United States during the assessed period. As already observed, the higher liquidity seems to have only an indirect effect on the price trend, which would react to the deflation tendency in the unstable economy but only if the new currency supply could mitigate the system crisis. It should be emphasized that the strong link connecting the cycles of the economy and the cyclical inflation, makes the two variables moving in a coordinated mode, so that if the recessionary climate is mitigated at the same time the deflationary price pressure is alleviated. 
Graph n. 4

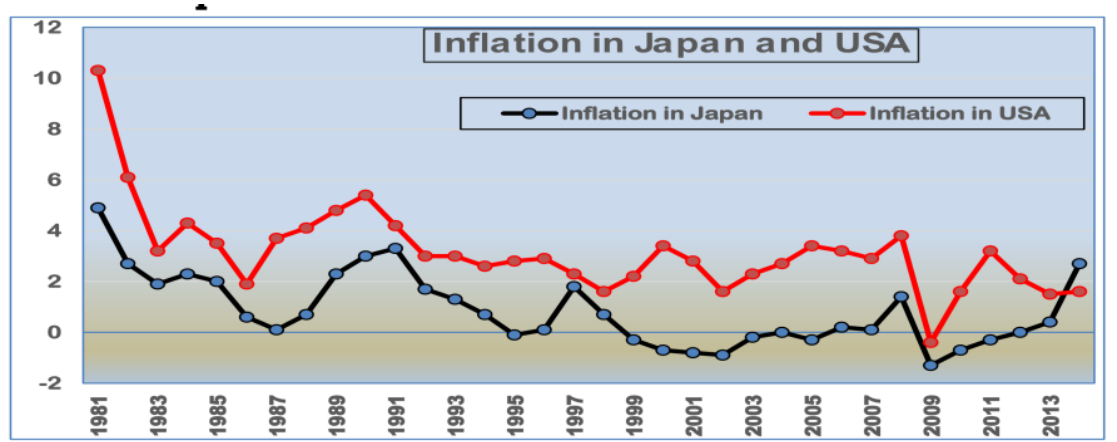

Graph n. 5

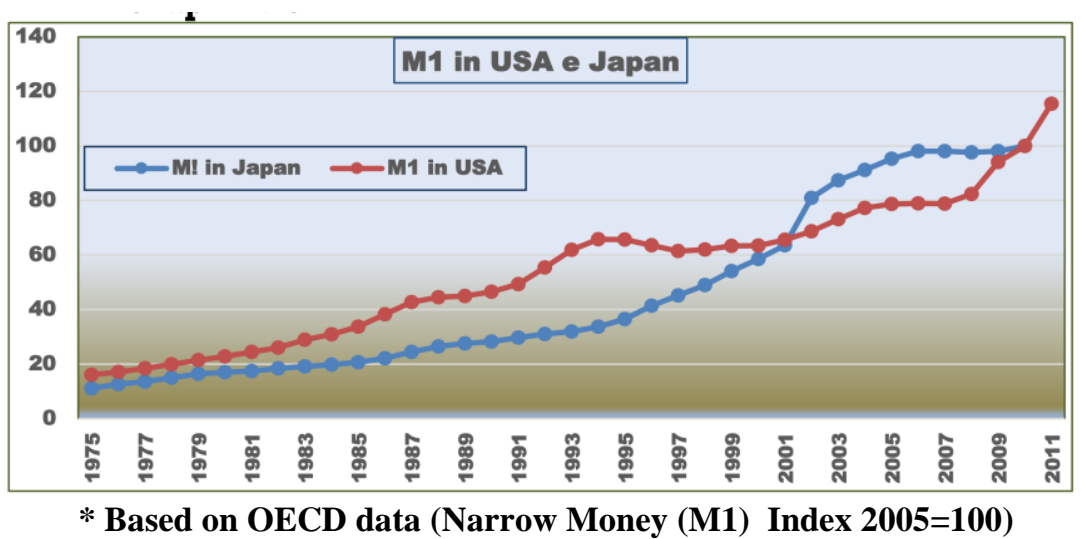

Considering this compelling and unavoidable bond, it seems reasonable to assume that the liquidity injections rapidly rising in Japan, during the period 1991-1995, gave a real contribution to the stability of the economy, which in these five years does not show recession and is maintaining anyway a low speed (average growth at $1.4 \%$ ). The economy resilience in the early nineties then was directly reflected on the deflation tendency of a post-speculative boom economy, resulting after that in a deflation mitigation. Thus, the modest inflation of the nineties slowly decreased and only in 1995 reached the zero level.

The Japanese story, somehow unusual and peculiar, deserves in fact an in-depth analysis, keeping an eye on the behaviour throughout the period from 1985 onwards. Analysing the Graph n. 6 we can notice that, since the eighties, the long parable followed by the Japanese inflation is ending in the 1986-87 biennium, descending almost to zero, and then going up under the heavy influence of the accelerated bubble. In other words, we believe that - excluding the peak period of irrational excess - the Japanese economy at least since 1986 became unstable with a deflation tendency. We must add that in the period 1986-1988, the currency reserves in Japan increased from 22 to 90 billion dollars. This great jump in reserves was accompanied by an increased growth of the monetary base from an average of $5 \%$ to about $15 \%$.

We would like to point out also that, in the biennium 1986-87, the interest rates are flattening towards the lowest decade level, following the prices on a descending trend, while the strong irrational pressure of the speculative bubble affects only the economy growth. Economic growth linked to the mounting boom is "virtual" and therefore it is not reflected on the main variables, starting with inflation and interest rates, which instead are languishing in the deflationary climate tendency of the economy. The values generated by the irrational growth linked to the boom, then will be swept away by the subsequent financial crisis.

Once more on the subject of deflation pre-financial crisis, should not deceive the small hump profile of the US inflation in the five years prior the financial crisis of 2008-2009 (Chart no. 4). The creeping deflation was installed in the US economy in the early 2000s. It is the deflationary stagnation of prices in America that allowed absorbing, without shocks, the strong fluctuations in crude oil prices, reaching almost $\$ 150$ a barrel in mid-2008, when the boom reaches its peak. 
Graph n. 6

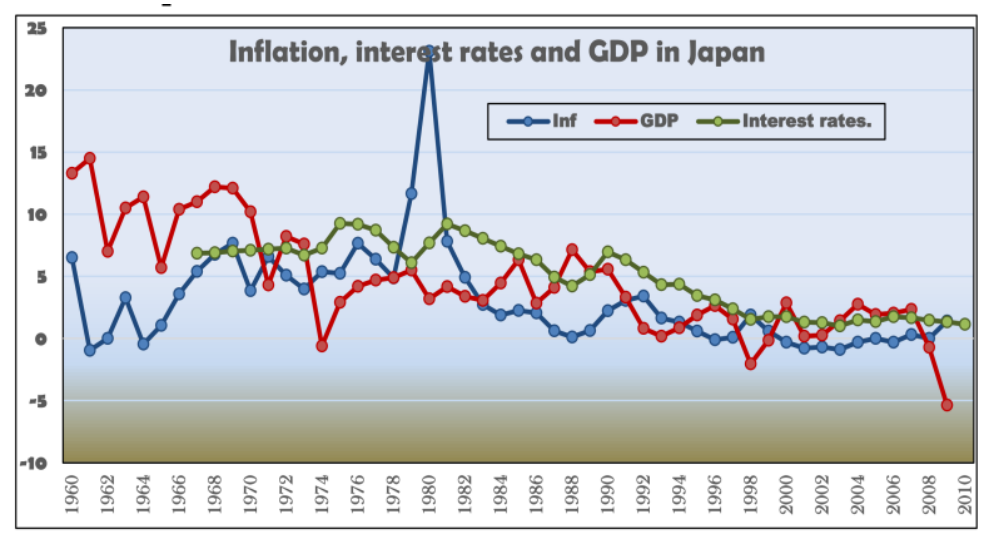

\section{* Based on OECD data}

Following the approach defining deflation as a symptom of an economic system instability, the crisis of the Japanese economy has been developed over a period starting in the eighties, when deflation appears, then evolving in a boom of irrational magnitude to end into a financial crisis long-lasting from nearly two decades.

More effective to fully outline the reality of Japan in the long period, certainly seems to be the profile of prices definitely deflationary since 2000 , while the economy is remaining weak, until the 2009 severe recession caused by the blows of the global financial crisis. Public debt is running up, passing from $96 \%$ in 1999 to $164 \%$ in terms of GDP in 2007 , to reach almost $250 \%$ in 2013. The money amount in denomination M1 doubled from 1999 to 2009, increasing from 53 to 102 (2005 index). However, the vicious cycle of the system tendency to depression and deflation is not broken. Indeed, throughout the years from 1991 to 2008, the average growth remains stable at around $1 \%$, nevertheless the deflationary movement is fixed at an average of $0.4 \%$ (-0.4\% during 2000-2007).

At this point, looking the instability worsening since 2000 , it is reasonable to question why the typical Keynesian interventions for the cycle correction are neutral in Japanese reality both on the deflation trend as well on the economic cycle performance. In addition, it should be examined the reason for the relative irrelevance of the 1998 recession to overcome the Japanese economy impasse. Recession, worth mentioning, partly caused by the measures taken by Prime

Minister Ryutaro Hashimoto, to correct the excess of public finance and to promote the rescue of the banks affected by the financial crisis and by the collapse of securities and real estate.

For the moment, it is clear that in the five years following the 1998-99 recession, the deflation made a negative quality jump and the economy remained stagnant. Therefore, there is no doubt that the turning point between the two periods before and after the recession has an important implication in order to decode the complex picture of the Japanese economy in the twenty years. The intuition of Prime Minister Hashimoto, who frankly stated "I see no future for Japan" without deep changes, seems to demonstrate the thesis that a real shock would be needed to reinstate the lost energy of the Land of the Rising Sun economy. A shock caused by a creative recession to purify the economy, made unstable by a finance conduct too exuberant with respect to the state of the real economy.

Well, it is reasonable to believe that the natural model acting when the economy is unstable relies on the recession as a "creative destruction", according to the Joseph Schumpeter model. During a financial crisis, the recession seems to play an active role for the realignment of the financial excess according to the economy real situation.

Going back to Japan, the fall into recession in 1998 does not seem to be linked directly to the sharp cut on the public budget implemented by the Hashimoto Government, considering nonetheless how the government deficit in that year has reached $90 \%$ in terms of GDP. A level of public debt that - as already mentioned - can help to keep down the economy growth. In any case, it seems reasonable to assume that the temporary shutdown of all therapies for the cycle resilience - imposed by the reformer Hashimoto - has given an even partial green light to the natural process for the unblocking of the altered system.

Unfortunately, the recession course (intended as "creative destruction") has not been able to fully deploy its effects in the system decongestion, because it was interrupted by a new extended program of interventions in the area of public works wanted by the new Government. Therefore, we are not able to say whether, if left free to act, a more prolonged recession would solve at least partially, the long financial crisis.

At this point, it becomes relevant the hypothesis that an economic system with a public debt exceeding $90-100 \%$ in terms of GDP, is incorporating toxins and is entering into a condition which can be defined as latent financial crisis. In other words, Japan would not come out from the financial crisis just because it was blocked for a long time in a condition of excessive debt, and not only in the public sector. Apparently, this deadlock does not seem to leave open any exit gate yet. That is why the Japan public debt reaches the threshold of 90\% in terms of GDP in the biennium 1998-1999, so that the decision to insist on Keynesian measures to fight the recession seems actually to have produced the unexpected effect of the inconsistency of repeated interventions to support the economy.

According to this view, it seems to show some fault the argument that Japan would be, and maybe still now is, for a long time struggling with a liquidity trap making ineffective its monetary policy. Certainly the economy in these circumstances can be taken by a sort of trap, but the reasons do not seem of a monetary nature but merely economic. 6 
This thesis, however, leaves open some doubt space. Within an economy in deflation for over a decade, it is somehow hard to believe that monetary policy, even if ineffective because of the block in nominal interest rates close to zero, could be in some way responsible for the lack of crisis solutions.

We are probably dealing with a misunderstanding about the validity of the monetary option; this misunderstanding is probably coming out from the fact that the economy instability occurs often with monetary phenomena (inflation or deflation). The instability, however, is always linked to economic factors and then inflation or deflation must be evaluated as messengers of the unstable condition, as well as signals of the schedule to be followed by the economic system in crisis, to be able to gradually return to a normal condition.

As already mentioned, the firm link between deflation and recession within a financial crisis is connecting without a doubt the recession - as a creative destruction - to deflation, as a messenger of the crisis deepness and a cooperating element in the hard recovery action. Therefore, it would be meaningless a direct action on deflation, because the driver of the combined mechanism recession-deflation is exactly the negative conjuncture inexorably affecting the nominal price decline. On the other hand, does not seem to subsist any feedback from the deflation to the conjuncture. According to this perspective, it is reasonable to believe that we could act on the economy in recession - e.g. with a large plan of public works - to mitigate the economic cycle, then to alleviate consequently the deflation. However, only in an indirect way, it becomes possible to mitigate the decline in prices, following the direction of unilateral link between economy in recession and deflation.

However, the indirect way to alleviate the situation and as a result to moderate the deflationary decline in prices would not be allowed in a system with excessive government debt. It would not be possible to use this option, if it has already abused with the repeated recourse to deficit spending, so pushing the national debt to exceed the threshold. In the case of Japan, then, the existence of a liquidity trap cannot be held as a primary cause of persistent stagnation, because liquidity has a role submitted to the economic cycle. As to say that is not ascertained a feedback made by the liquidity, considered as a substantial component of the price system, to the negative cycle of the economy, in order to condition it. In any case, the problem does not seem could be faced through monetary instruments with satisfying results, because in this specific state of growing instability each channel seems to be precluded for the monetary policy.

\section{Confirmation attempt through the analysis of the variables}

According to the hypothesis described above, the persistent recurrence of interventions to support the economy by generous doses of liquidity and public spending over the time could have become the source of the deflation-prolonged season afflicting Japan. In particular, the phenomenon of the low incidence of supporting interventions becomes more evident since 1998, when the method of Ryutaro Hashimoto Government, intending to capitalize the banks and to cut the state budget, undergoes a sharp reversal with the new Prime Minister Keizō Obuchi. To support the economy, it was decided to start a pharaonic program of public interventions, so projecting the public debt far beyond $90 \%$ in terms of GDP and then progressively up to $230 \%$ of GDP.

Since that time, however, the large amount of public resources put in place are not showing a significant effect on the economy, while it is reasonable to presume that a persistent deflationary climate has been promoted (an average of 0.4\% per year until 2005). Therefore, is hard not to connect the worsening economic climate and especially the persistent deflation in the decision to force vigorously the manoeuvre pro-economy.

\section{Graph n. 7}

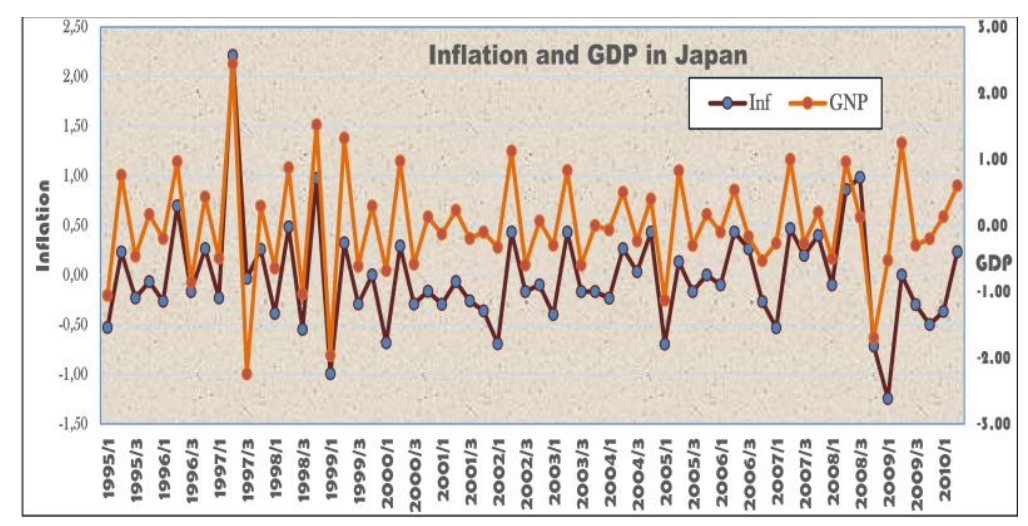

* Based on OECD data

At this regard, it should be reminded that, from 2000 until 2007 (the year when the economy course seems to improve under the incentive of an abnormal worldwide economic trend) the greater instability settled in the Japanese economy activated some recurring cyclical fluctuation in the economy. Short economic cycles followed in parallel by inflation cycles (with a negative average). The fastened rhythm of the economy cycle and in parallel the automatic inflation movement (deflation tendency) is displayed in the Graph n. 7, well showing the two variables trend, on a quarterly basis, for the period between 1995 and 2010.

The slight divergence emerging in that period between the GDP and the inflation profiles, is linked also to the presence of other variables. Variables that, due to the growing instability, entered into competition with the relation, otherwise strict and reliable, between GDP and inflation. In fact, we suppose that the rush imposed by the inexhaustible growth of 
public debt interferes with the relationship between inflation and GDP, so causing an acceleration in the tendency to deflation in the Japanese economy. Therefore, the result is a flattening of the inflation profile, which develops almost in negative area, while the product retains in short-term even a modest cyclical configuration. A similar temporary connection is established between the money variation, in M1 denomination, and inflation. The latter indeed is showing a downward trend, inversely correlated with the liquidity, which is growing in order to finance the debt issuance.

For confirmation of this hypothesis, which is awkwardly linking the trend of GDP with the inflation course (negative), together with high public debt and liquidity, we can verify if the supposed link of the analysed variables actually does exist. To do this, we should examine their trend and relations in the specific case of Japan. The period under observation, as already said, is running between 2000 and 2005, rightly the years when is going on the situation of a public debt high level (> 90\% of GDP), while the global boom effects are not yet so relevant. In fact, the boom will end only in the late 2008. 8

To verify the relationship between the abovementioned variables, we proceed processing the regression equation (1) relating the GDP variation to the trend of the "inflation" regressor, supported by the predictors "Public Debt", "Unemployment Rate" and liquidity in its " M1 " denomination.

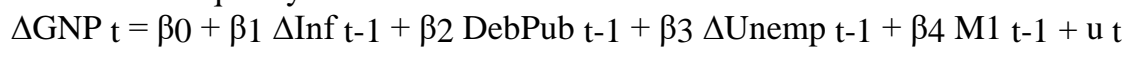

Please note that:

- $\boldsymbol{\beta 0 , \beta 1 , \beta 2 , \beta 3 , \beta 4}$ are unknown coefficients, calculated through the OLS estimators

- $\triangle$ GDPt-1 is the dependent variable relating to the economic growth rate (GDP)

- $\Delta$ Inft-1 is the regressor of the inflation variation

- Deb.Pbt-1 is the predictor relating to the public debt in terms of GNP

- $\Delta$ Unempt-1 is the predictor relating to the unemployment

- M1t-1 is the predictor relating to the liquidity (M1)

The regression function (1) is able to provide, with some approximation, the predicted GDP values at a time, based on developments in the Inflation regressor together with the contribution of information supplied by the trend of variables with predictor functions. Within a stable economy, the harmonious development of the economy according to its potential makes possible the changes predictability of each variable, taking into account the mutual past behaviour. Within a stability condition, then, the result provided by equation 1 is considerably close to its real value. Instead, in the case of an unstable economy, the forecasting ability obtained from the past values regression is fading, because the relative trend of the variables loses its general harmony and consonance, for the concerted effect of reciprocal conflicting influences.

As mentioned, in the case of instability a narrow and concerted connection is created, between the performances of GDP and Inflation (basically negative), so that the variation experienced by the first is transmitted and adopted by the Inflation. It follows that a relationship is created of simultaneous causality, altering the result of equation 1.

To remove from the forecasting calculation the effects of simultaneous causality between the deflation and the economy recessionary trend, we need to identify the sequence of "Inflation" exogenous part (unrelated) against the "GDP" trend. Through this action we can distinguish the exogenous portion from the other portion of the same variable, which instead is endogenous (correlated) of the GDP values. This procedure, through the instrumental estimator method called TSLS (Two Stage Least Squares), is requiring the identification of one or more instruments (relevant and exogenous in relation to the income), allowing to isolate the $\mathbf{X}$ part uncorrelated with the ui error.

In the first stage, the process is making use of an exogenous component $\mathbf{Z}$ to rectify the causality between the two variables. We use the equation:

$$
\mathrm{X}_{\mathrm{i}}=\pi 0+\pi 1 \mathrm{Zi}+\mathrm{vi}
$$

which is breaking down the dependent variable "inflation" in the related part and in the remaining uncorrelated one. The component $\boldsymbol{\pi 0}+\boldsymbol{\pi} \mathbf{1} \mathbf{Z} \mathbf{i}$ is the $\mathbf{X i}$ part that can be predicted by $\mathbf{Z i}$. As $\mathbf{Z}_{\mathbf{i}}$ is exogenous, then this part of $\mathbf{X i}_{\mathbf{i}}$ is also exogenous. The other part "vi" is the component of regressor $\mathbf{X i}$, then is correlated instead to the error ui. The uncorrelated component of $\mathbf{X i}$ will be used then in the equation 1 (thus ignoring the error vi), which therefore becomes as follows:

$$
\mathrm{Yi}_{\mathrm{i}}=\beta 0+\beta 1\left(\pi 0+\pi 1 \mathrm{Z}_{\mathrm{i}}\right)+\beta 2 \mathrm{~W} 1+\beta 2 \mathrm{~W}_{2}+\beta 3 \mathrm{~W}_{2}+\mathrm{ui}
$$

In the selection of a suitable tool which should be relevant and exogenous, the "current account balance" has been used, which we presume being little or even not correlated with inflation in the related year. As next 'candidate' we choose the long term interest rate (Longterm.rate) that can be considered exogenous against the inflation current trend.

The regression at its first stage, therefore, includes the predictors of (1) concerning the consistency of the "Public debt", of the "Unemployment" and of "M1", as well as the exogenous variables "Current account balance" and "Long- term rates". It follows that:

$\Delta$ Inft-1 $=\pi 0 \quad+\pi$ Deb.Pbt- $1+\pi 2 \quad \Delta$ Unempt- $1+\pi 3 \quad$ M1t- $+\pi 4$ Longtm.ratet $-1+\pi$ Accountt $1+\mathrm{vt}$ 
In this case, the instability condition due to a recurring use of Keynesian manoeuvres with a crescendo of public debt, involves a particular behaviour of the interested variables. In these circumstances, there is a close relationship between "Inflation" and "GDP" with the effects of a simultaneous causality, which should be eliminated in some way. Not only that. Even the variables "Public debt" and "M1" liquidity, will end up to apply a specific influence altering, each one for its own part, the developments in both inflation and economy.

As above mentioned, when the public debt size exceeds and remains well above $90 \%$ threshold, the crescendo of this variable together with the connected M1 will influence directly, with a declining trend, the economic cycle course. In other words, it is created a multiple simultaneous causality involving the three variables concerned -Inflation, Public $d e b t$ and $M 1$ - each one with a specific interference on the performance of the GDP and of nominal prices. In other words, the tension exerted by the growing public debt is pushing down the economy cycle and the inflation; likewise is doing the variable M1 dragged upward by the fiscal policy and by the accommodating monetary policy.

Therefore, we need to rectify the effects of simultaneous causality also for the "public debt" and "M1" included in the equation 1, using also for these variables the TSLS procedure, in order to eliminate the effects deforming the estimate forecasts. To do this, for both "public debt" and "M1" we will proceed to process the first stage regression as follows:

$$
\begin{aligned}
& \text { Deb.Pbt- } 1=\pi 0+\pi 1 \quad \Delta \text { Inft- } 1+\pi 2 \Delta \text { Unempt-1 }+\pi 3 \text { M1 t-1 }+\pi 4 \text { Longtm.rate } \mathrm{t}-1+\pi 5 \text { CurrentAccount t- }+\mathrm{vt} \\
& \mathrm{M} 1 \mathrm{t}-1=\pi 0+\pi 1 \quad \Delta \text { Inft- } 1+\pi 2 \Delta \text { Unempt- } 1+\pi 3 \text { Deb.Pbt- } 1+\pi 4 \text { Longtm.rate } \mathrm{t}-1+\pi 5 \text { CurrentAccount } \mathrm{t}-1+\mathrm{vt}
\end{aligned}
$$

All the values obtained from equations (2) (3) and (4) of the TSLS first stage, are the uncorrelated values which should substitute in (1) all the corresponding values of $\Delta$ Inft-1, Deb.Pbt-1 and M1 $\mathrm{t}-1$, to be able to do the TSLS estimate of $\beta 1$, $\beta 2, \beta 3, \beta 4$. In the case of a detected simultaneous causality, the TSLS estimator should provide results reducing the forecasting error. This possibility -if and when ascertained- would confirm that the instability derived from public indebtedness excess, brings to:

- A strong and clear link between the economic cycle and the cyclical inflation, and consequently the recession or even an economic growth close to zero induces a negative sign to the price system. As the conjuncture is proceeding following cycles usually short, in parallel some modest increases are occurring in inflation followed by stronger negative signs, with the usual result of a creeping deflation;

- An additional relationship between the rising Public debt and the Economy performance, resulting in a penalized growth. In fact, there is a balance between the effect (weak) produced on aggregate demand by the higher public spending and the hesitation effect on consumption and investment caused by an excessive indebtedness. Therefore, the growth profile becomes even more flat, while there is an increased tendency to deflation in the economic system.

Based on these methodological premises, we carried on the calculation of the pseudo-forecasts, primarily with the equation (1), without making adjustments in its linear setting. Subsequently, we passed to the calculation adjustment through the use of the TSLS procedure, which is able to eliminate as much as possible the simultaneous causality distortion, derived from the link created between the variables "GDP", "Inflation", "Public debt" and "M1 ".

In the Table n. 1 are exposed in sequence: the observation period, the forecast according to (1), the forecast with the TSLS procedure and finally the real data on GDP during the 1st quarter 2005. In the Table n. 2, the same sequence is repeated, but referring to the 3rd quarter of 2004. In the same tables are exposed, also for a simple comparison of the results obtained by the same year forecast, the data for two countries that, in the same period of time, have maintained a good behaviour in terms of public debt consistency and economy relative stability. The countries selected for this comparison are Germany (60\% of public debt in terms of GDP) and Australia (10\% of public debt). As we have already stated, in the case of countries maintaining a relative stability state, the GDP trend should follow a regular profile and therefore evolving accordingly with the other variables; this will allow obtaining reliable results by the use of equation (1), without adjustments.

Tables n. 1 and n. 2 are showing a clear improvement of the forecast results obtained through the TSLS procedure concerning Japan, thus providing a good signal about the relations system between variables that is established when the threshold of excessive public debt is exceeded. Therefore, it looks like a result confirming the close relationship that is binding, within an unstable economy, the weak or negative economic cycle and the tendency to deflation. In this altered context, the interference of an excessive public debt tends to minimize the development potentials and then to push down the nominal prices. So new even massive Keynesian support measures and the liquidity increase to finance the debt are showing to have only neutral effects on the conjuncture course and then they seem to reinforce the deflationary trend of the economy. 
Table n. 1

\begin{tabular}{|c|c|c|c|c|}
\hline Countries & Observed period & $\begin{array}{l}\text { Inflation calculated } \\
\text { with regression function }\end{array}$ & $\begin{array}{l}\text { Inflation calculated } \\
\text { with TSLS method }\end{array}$ & $\begin{array}{l}\text { Real } \\
\text { Inflation } \\
2005 / 1\end{array}$ \\
\hline Japan * & $1988 / 3-2004 / 4$ & $\begin{array}{c}0,21 \\
E P=0,641 \quad \text { Stat. } F=2,179\end{array}$ & $\begin{array}{ll} & 0,45 \\
E P=0,722 & \text { Stat. } F=0,611\end{array}$ & 0,71 \\
\hline Germany * & $1988 / 3-2004 / 4$ & $\begin{array}{c}0,03 \\
\text { EP }=0,551 \text { Stat. } F=0,490\end{array}$ & $=$ & 0,14 \\
\hline Australia * & $1988 / 3-2004 / 4$ & $\begin{array}{c}0,74 \\
E P=0,475\end{array}$ & $=$ & 1,02 \\
\hline
\end{tabular}

* Inflation calculated and real at 2005 first quarter

Table n. 2

\begin{tabular}{|c|c|c|c|c|}
\hline Countries & Observed period & $\begin{array}{l}\text { Inflation calculated } \\
\text { with regression function }\end{array}$ & $\begin{array}{l}\text { Inflation calculated } \\
\text { with TSLS method }\end{array}$ & $\begin{array}{l}\text { Real } \\
\text { Inflation } \\
2004 / 3\end{array}$ \\
\hline \multirow[t]{2}{*}{ Japan * } & \multirow[t]{2}{*}{$1988 / 3-2004 / 4$} & $-0,01$ & 0,64 & 0,59 \\
\hline & & $E P=0,639$ Stat. $F=2,361$ & $E P=0,718$ Stat. $F=0,881$ & \\
\hline \multirow[t]{2}{*}{ Germany* } & \multirow[t]{2}{*}{$1988 / 3-2004 / 4$} & 0,11 & \multirow[b]{2}{*}{$=$} & \multirow[t]{2}{*}{0,28} \\
\hline & & $E P=0,577$ Stat. $F=0,258$ & & \\
\hline \multirow[t]{2}{*}{ Australia * } & \multirow[t]{2}{*}{$1988 / 3-2004 / 4$} & 0,59 & & \multirow[t]{2}{*}{0,71} \\
\hline & & $E P=0,4996$ Stat. $F=2,556$ & $=$ & \\
\hline
\end{tabular}

* Inflation calculated and real at 2004 third quarter

Even though it may be peculiar nevertheless, the liquidity excess put in place to finance government measures supporting the economy seems to promote the deflation tendency within an unstable economy. Then it is confirmed that deflation is not a monetary occurrence but a "messenger" - through the currency - that is advising about the extreme vulnerability faced by the economy. From this point of view, it would not be acceptable the theory that the Japanese economy is suffering due to a liquidity trouble.

In principle, we must agree that the constantly deflationary state would push the traditional monetary policy to a deadlock, as it would be no longer available any option relating to the manoeuvre of interest rates. However, this does not appear enough to say that this condition involves a supposed liquidity trap. It is indeed quite difficult to accept that an economic giant like Japan could be submitted to such a trap for over a decade, in spite of its economy strong global nature. Also because, over the threshold with the public debt, the economy system seems to get into a pseudo financial crisis. Therefore, the modest fervour produced by the never-ending interventions to support the economy becomes virtual (i.e. will be erased by the breathless mini cycles pervading the unstable economy) and therefore will not be reflected on price trend. Prices, in fact, are subject to the real economy evolution: as the real economy is actually in recession, the deflationary drift of the economy has the tendency to be accentuated.

It follows that, in a strange contradiction with the quantitative theory of currency, the increase of the liquidity created for the economy strength becomes an indirect causal factor for the slow decline of the price system. Consequently, the quantitative theory of currency is it contradicted? I would say rather that the economy allocation, essentially virtual because fed by the liquidity excess, should not be included in the calculation of the money quantity. Thus, we could justify the remarkable fact that in the period under review (2000-2005) the inflation is generally tending to zero, while the GDP is prospecting a growth, though weak, of about $1.5 \%$ annual.

The virtual character of the economic growth portion linked to the overflow of Government measures would have therefore just a temporary effect, a kind of virtual quantity for the economy growth that can be removed with unusual rapidity, if the economic system would impact with an external shock. In this case, the consequent recession would be surprisingly hard, exactly because of the removal of that virtual deadweight. For Japan, the recession pushing away (though partially) the virtual load produced by the economy blemished by an excessive public spending, occurred only in 2009 , as a result of the global financial crisis. We should recall that Japan remained free from the real estate bubble that affected the majority of industrialized countries during the years preceding the 2008-2009 crisis. The severe recession of $2009(-5.4 \%)$ that hit the Land of the Rising Sun, should be considered partly due to a sort of vanishing of the half-bubble created by the public debt excess.

A similar effect occurred in other countries struggling with a long-standing huge debt, as in the case of Italy, though only marginally affected by the real estate bubble and not exposed to a possible collapse of the leading Banking Institutes. For the Beautiful Country, the 2009 deep recession (-5\%) was almost twice of France and the United States and anyway deeper of England, although all these countries had the primary leading role in the speculative bubble and have been subject to a deep financial crisis.

\section{Conclusions}

The prolonged instability of economic systems inhibited for the continued use of deficit spending manoeuvres, could be held responsible for the passage of the Japanese economy from the financial crisis instability of the nineties to the pseudo financial crisis for excessive public debt starting since 1999. As already mentioned, the increase in liquid availabilities driven by the public debt expansion seems to become neutral about the price trend, which has a deflation tendency in Japan. Then it would make no sense trying to correct the deflation through monetary interventions, proposing 
an even higher inflation target.

As saying that in an unstable economy, the monetary phenomenon seems to be able to manage the money supply, making neutral within the market the excesses in the case of deflation or accelerating the money supply creation (M3), consistent with the accelerated motion of the inflationary process. This is what is happening in Japan hit by deflation for over a decade, though overflowed by massive new liquidity. This is what happened during the seventies in Italy and in most countries, when the force of inflation was dragging the currency creation and the circulation speed, in order to support the process of nominal price growth.

\section{Bibliography}

[1].Ben S. BERNANKE “Essays on the Great Depression” Princeton University Press - Princeton, New Jersey - 2000

[2].Ben S. BERNANKE "Nonmonetary Effects of the Financial Crisis in the Propagation of Great Depression" The American Economic Review - 1983

[3].Thomas F. CARGILL, “The political economy in Japanese monetary policy" - Michael HUTCHINSON,Massachusetts Institute of Technology - 1997 Ito TAKATOSHY

[4].E. CARDOSO "Inflation and Poverty in NBER Working Paper \# 4006, year 1992

[5].Giovanni COSSIGA "Un approccio alla teoria dell'inflazione" - Rivista Milanese di

[6].economia - 2001 n. 71 -72 anno 1999, Milano, Cariplo - Laterza

[7].-“La recessione e l'inflazione" - in Mondo Bancario - n. 5 settembre - ottobre 2000

[8]."The Instability of Economic Systems and speculative market. The case of China." SCHOLEDGE INTERNATIONAL JOURNAL OF MANAGEMENT \& DEVELOPMENT -Vol 2, No 9 (2015)

[9].Rudiger DORNBUSCH, “Moderate Inflation.” 1993. World Bank Economic Stanley FISCHER Review 7, 1-44

[10]. Charles KINDLEBERER “The World in Depression: 1929-1939” (University of California Press, 1973)

[11]. Paul R. KRUGMANN“It's baaack: Japan's slump and the return of the Liquidity

[12]. Trap" - Brooking Papers on Economic Activity -Vol. 1998, n. 2, 137-205

[13]. Paul R. KRUGMANN “The return of Depression Economics and the crisis of 2008” W.W. Northon \& Company Ney York London

[14]. J. Richard HICKS “Mr. Keynes and the classics”; A suggested Interpretation.” Econometrica, Vol. 5 April 1937

[15]. Leon N. LINDBERG, Michael S. MAIER, Brian BARRY "The Politics of Inflation and Economic Stagnation" S. Brookings Institution - Washington D.C.

[16]. J.F. BOSCHEN, L.O. MILLS “Tests of long-run neutrality using permanent monetary

[17]. and real shocks" in Journal of Monetary Economics, vol. 35 Febbraio 25-44, 1995.

[18]. Edmund PHELPS“Microeconomic Foundations of Employment and Inflation Theory“ (Norton, 1970)

[19]. Nouriel ROUBINI“ Crisis Economics. A crash course in future finance” Stephen MIHM The penguin pressNew York, 2010

[20]. J. Patrick RAINES, “Debt, Innovation and Deflation: The Theories of Fisher,

[21]. G. Charles LEATHERS Schumpeter and Minsky”-Edward. Elgar Massachusetts USA

A. Gary SHILLING "Deflation. How survive and thrive in coming wave of deflation” 2001

[22]. Peter TEMIN "Lesson from the Great Depression" The MIT Press Cambridge, Massachusetts

[23]. IMF "International Financial Statistics" - Database, various years

[24]. OECD “ OECD. Stat - Database, various years 